\title{
Sustainability crises are crises of relationship: Learning from Nyikina ecology and ethics
}

\author{
Annie Milgin $^{1}$ | Linda Nardea ${ }^{1}$ | Hilda Grey ${ }^{1}$ | Sarah Laborde ${ }^{2}$ (D) | Sue Jackson ${ }^{2}$
}

${ }^{1}$ Walalakoo Aboriginal Corporation, Derby, WA, Australia

${ }^{2}$ Australian Rivers Institute, Griffith

University, Nathan, QId, Australia

\section{Correspondence}

Sarah Laborde

Email: s.laborde@griffith.edu.au

Funding information

National Environmental Science Program; Northern Australia Environmental Resources Hub

Handling Editor: Priscilla Wehi

\begin{abstract}
1. In the context of the current global ecological and climate crisis, there are increasing calls in the environmental sustainability literature to recognize the validity and value of Indigenous knowledge systems. At the same time, the limitations of utilitarian frameworks of environmental decision-making are becoming clearer to many researchers and practitioners, who see a need to engage with the underlying ethical questions of sustainability, such as 'What is to be sustained, and for the benefit of which forms of life?'

2. At the interface between these two urgent imperatives, lies a question that has remained marginal in the sustainability literature: How can the environmental ethics of Indigenous societies help frame sustainability science and practice?

3. Based on a case study from Nyikina Country in northern Australia, we show here how the ethical principles embedded in an Indigenous hydro-ecological knowledge system can help reframe, and address, sustainability crises as crises of relationships.

4. Learning from the linkages between custodial and hydro-ecological relationships in Nyikina Country, we discuss three contributions of relational thinking to sustainability research and practice. First, at a governance level, the need to embed ontological plurality into state environmental policy. Second, at a management level, the priority of continued communication between the Country and its custodians. Third, at the level of knowledge production, the imperative for sustainability researchers and practitioners to bring to their research process the relational qualities of pluralism, reciprocity and care that are at the core of Nyikina and other Indigenous ecological ethics.
\end{abstract}

\section{KEYWORDS}

Australian Aboriginal philosophy, care, ecology, ethics, relational ontology, water

\section{1 | INTRODUCTION}

Sustainability scholars are increasingly calling for Indigenous expertise to inform environmental science (Jardine, 2019; Reyes-García \&
Benyei, 2019). This call has been associated with a diversity of research endeavours, from the incorporation of selected elements of Indigenous peoples' knowledge of ecological processes into Western environmental research and management (Ban et al., 2018; Ens

This is an open access article under the terms of the Creative Commons Attribution License, which permits use, distribution and reproduction in any medium, provided the original work is properly cited.

(c) 2020 The Authors. People and Nature published by John Wiley \& Sons Ltd on behalf of British Ecological Society 
et al., 2015), to analyses by Indigenous scholars of Indigenous frameworks for healthy and ethical human-environment relations (Nelson \& Shilling, 2018; Roberts et al., 1995; Salmón, 2000). Currently, such research tends to occur within an 'integrative space' on this spectrum (Chilisa, 2017), where Indigenous ways of knowing are recognized as bodies of expertise in their own right and attempts are made at 'integrating' or 'weaving' Western and Indigenous approaches and understandings to enhance the sustainability of human-environment relations (Mistry \& Berardi, 2016; Tengö et al., 2017).

At the same time, with intensifying environmental pressures and enhanced human ability to engineer socio-natural systems, the importance of thinking about the ethical underpinnings of sustainability-the question of what is to be sustained, and for whose benefit (humans and non-humans)-has grown (Minteer, 2012). Environmental sustainability problems have been understood as largely ethical problems since the 1960s, including in foundational texts of sustainability science, such as the Club de Rome's Limits to Growth (Meadows et al., 1972). The field of environmental ethics has since developed (Kawall, 2017), giving rise to a call from environmental philosophers for a 'multicultural environmental ethics' to foster understanding and dialogue across traditions of human-environment interactions and help address global sustainability crises (Callicott, 2001).

Analyses of the ethical underpinnings of human-environment relations in Indigenous knowledge systems intersect these two foci of environmental ethics and Indigenous social-ecological studies, and they have the potential to assist in contributing to both. Indigenous scholars and their collaborators have shown that a non-anthropocentric relational ethos, by which people interact with non-humans in their environment as relations or kin, rather than an external nature or objectified resource, is a core feature common to many Indigenous ecological knowledge systems (Kimmerer, 2013; Nelson \& Shilling, 2018; Pierotti \& Wildcat, 2000). There are numerous published examples of concepts associated with such humannature relationality, specific to their geographical, linguistic and socio-cultural contexts. These include the Rarámuri term iwigara, described by Salmón as 'the total interconnectedness and integration of all life in the Sierra Madres, physical and spiritual' (2000, p. 1328). From Hawaii, authors Kealiikanakaoleohaililani and Giardina explain that 'the social-ecological reality of belonging to and being connected with the surrounding environment is simply depicted in familial terms such as [...] kama'äina, child of the land, or one who is physically, psychologically, biologically and genealogically inseparable from the surrounding environment' (2016, p. 64). From Aotearoa (New Zealand), the Māori term Whakapapa is explained by Te Ahukaramū Charles Royal as 'express[ing] our [Māori] need for kinship with the world. They [Whakapapa] describe the relationships between humans and the rest of nature' (2007). These contributions, along with insights from environmental anthropology (e.g. Ingold, 2006; Rose, 2005) and more recent research in critical human geography and political ecology (e.g. Bawaka Country et al., 2015; Blaser, 2018; Jackson \& Palmer, 2015), constitute a rich body of literature articulating relational practices and intersecting Indigenous cosmologies. Western philosophers have also proposed relational understandings of human-environment interactions (e.g. Ingold, 2006; Næss, 1973) and discussed their ethical and political implications (Latour, 1999).

Such lines of research have been relatively influential in environmental humanities and social sciences disciplines; however, they have not permeated sustainability science and practice significantly enough to alter the utilitarian frameworks that still dominate prescriptions for and evaluations of sustainability. In Australia for example, there has been a substantial growth in Aboriginal community-based environmental programmes (Altman \& Kerins, 2012). Referred to as 'Caring for Country' initiatives, they must conform to a 'conservation-as-development' framework to receive government funding. While in practice, they do facilitate the presence of Aboriginal custodians on their Country, for example as elders join trips with ranger teams, Caring for Country programmes are not focused on maintaining relationships of care between custodians and a sentient Country but on linking employment aspirations of mostly disadvantaged communities with an environmental agenda that stresses conservation targets via material changes in biodiversity (both worthwhile objectives nonetheless). The associated shift in environmental discourse has been found to 'lack any profound challenge to the conceptual roots of mainstream natural resource management' (Jackson \& Palmer, 2015, p. 127).

The notion of relational value has been proposed internationally in part in an effort to address the lack of consideration of the relational component of Indigenous and local perspectives at the sustainability science-policy interface (Chan et al., 2018; Sheremata, 2018). For instance, it was included as a kind of anthropocentric non-instrumental value (Himes \& Muraca, 2018) in the global Inter-Governmental Panel on Biodiversity and Ecosystem Services (IPBES) framework (Díaz et al., 2018). The recent 'relational turn' in the sustainability literature, illustrated by the growing popularity of the relational values concept and by the emergence of this journal, represents an important step forward for the consideration of relationality in sustainability science and practice as it broadens the scope of dominant approaches of ecosystem services valuation (Gould et al., 2019; Stålhammar \& Thorén, 2019). However, the associated anthropocentric ethical stance (e.g. expressed by IPBES' aim to assess 'Nature's contributions to people'-Díaz et al., 2018; emphasis added) perpetuates the unidirectional nature of the ecosystem service concept. Despite its aim to be inclusive of Indigenous knowledge systems by, for example, acknowledging the validity of a Mother Earth framework, it is unclear whether IPBES assessments will explicitly consider the diverse linkages embedded in reciprocal human-environment relationships (Borie \& Hulme, 2015; DíazReviriego et al., 2019)-especially the responsibilities of humans to other forms of life that are central to many Indigenous knowledge systems (e.g. Nelson \& Shilling, 2018; Salmón, 2000).

We argue here, based on a Nyikina Aboriginal Australian perspective on sustainability, that there are further benefits in considering the potential of relationality, not only as a value concept that may improve assessments of the benefits to humans from other forms of life but also as an overarching framework for human-environment 
relations that has a basis in an ethics of care. We describe elements of Nyikina knowledge of Nyikina Country ${ }^{1}$ that are embedded in the intrinsic connection between hydro-ecological and ethical components. We show how a Nyikina relational ethics shapes socialecological sustainability within Nyikina Country. Lastly, we derive key principles from the case study, which we hope can expand and enhance sustainability research and practice.

Aboriginal peoples' occupation of the Kimberley region of Western Australia has been shown to date back at least 50,000 years (Veth et al., 2019). Nyikina Country is in the West Kimberley (Figure 1), and it is where many generations of Nyikina people have maintained language, stories and law. Today, most of Nyikina Country is managed through Walalakoo Aboriginal Corporation, of which the first three authors are directors. Annie, Linda and Hilda are also contributors to the Walalakoo Healthy Country Plan, premised on the following statement: 'Our ancestors passed on the obligation to look after Mardoowarra [Fitzroy River] and our country from generation to generation' (2017, p. 4). The Mardoowarra catchment, of which Nyikina Country represents a significant proportion (Figure 1), is currently the subject of public debate about land and water use, with different ethical claims underpinning competing visions for development. These visions range from the promotion of agricultural intensification based on a perception that abundant wet-season flows are wasted when not captured for farming, to a conservationist perspective that depicts the Fitzroy as a relatively pristine river system in need of protection, all the more because it is a heritage-listed landscape and home to critically endangered animals (Jackson et al., 2008). A statement by Aboriginal peoples (including Nyikina), in response to plans to develop the Fitzroy River, has expressed a 'third alternative' (see also Pierotti \& Wildcat, 2000). In this view, the river is a sentient ancestral being and Traditional Owners have a custodial responsibility to maintain a reciprocal relationship with it. It is a perspective that does not preclude

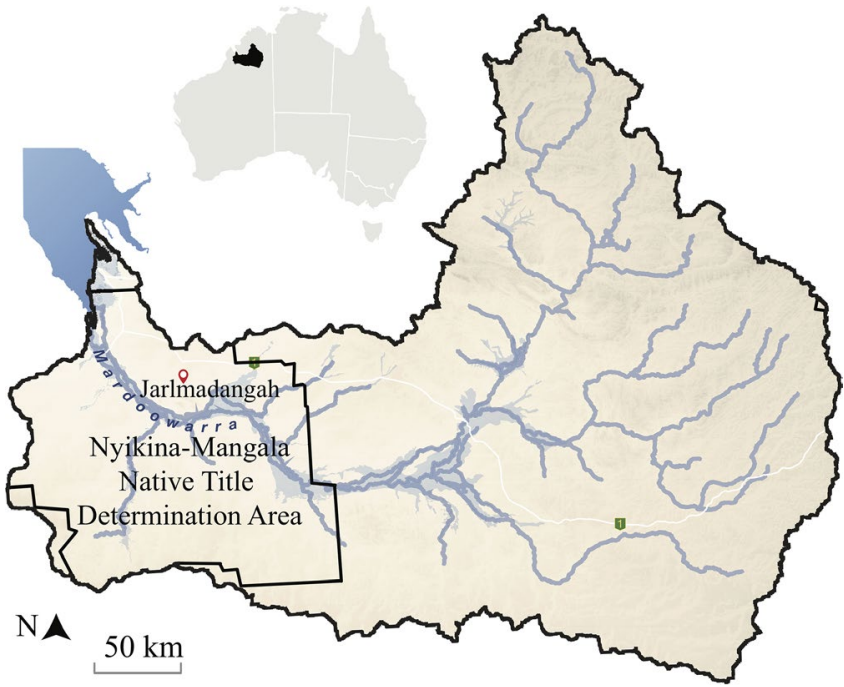

FIGURE 1 Map of the Mardoowarra-Fitzroy River catchment (outer black outline) and the Nyikina-Mangala Native Title Determination area, managed by Walalakoo Aboriginal Corporation (inner black outline). Jarlmadangah is the small community where Annie, Linda and Hilda were living for the duration of the research, and where our collaborative work was based development of land and water, but rather frames it within an Indigenous philosophy (Poelina et al., 2019). Our case study articulates this relational perspective through the study of Nyikina knowledge of ecological relationships (including the behaviour of water) and ethics.

We aim in this paper to describe elements of Nyikina ecology in the etymological sense of the term ecology: a discourse or story (from the ancient Greek lógos), about family relations within a home or habitation (from the ancient Greek oikos). The Nyikina notion of the ecological is deeply social, because everything, including people and water, is part of the oikos (eco in ecology). Therefore, our use of 'ecological' in this paper includes people, as part of an ecological and social network of relations between humans and non-humans that Enrique Salmón called 'kincentric ecology' (2000), drawing on similar observations from a Rarámuri perspective. Other social-ecological models developed by Indigenous researchers and their collaborators have emphasized the fundamental importance of the sentient land for acquiring and sharing knowledge, for example Simpson's descriptions of Nishnaabeg epistemology (2017), those of Walsh et al. (2013) and Holmes and Jampijinpa (2013) whose frameworks of ecological knowledge are, respectively, grounded in Anpernirrentye and Walpiri countries. We use the term ethics to describe the set of norms and behaviours that are accepted as being 'right' or appropriate by and for Nyikina people, in the context of their Country. We use ethos to designate the tacit component of this ethics, which is embedded in social institutions, bodies and places, in a non-prescriptive way. ${ }^{2}$ Finally, Nyikina law, as we refer to it in this paper, provides the basis for Nyikina ethics and ethos, and encompasses it. It is at once ancestral, continuing and evolving. A helpful description of the commonalities between Aboriginal laws across Australia was proposed by Aboriginal lawyer Irene Watson: 'the knowledge of the law comes through the living of it, as law is lived, sung, danced, painted, eaten, walked upon (...); law lives in all things. It is law that holds the world together as it lives inside and outside of all things. (...) Law is different to the European idea of sovereignty, different in that it is not imposed by force of arms and does not exclude in its embrace, it envelops all things. (...) It holds a continuity as there is no beginning or ending, for the constant cycles of life are held together by law' (2002, p. 255).

\section{2 | METHODS}

Our research team is comprised of three Nyikina and two nonNyikina researchers. The first three authors, Annie Milgin, Linda Nardea and Hilda Grey, have led Indigenous environmental planning and management activities, including those of Walalakoo Aboriginal Corporation's Healthy Country Committee, and have recorded and transmitted Nyikina creation stories, language and knowledge of edible and medicinal plants (Milgin, 2018). They are recognized as senior Nyikina women and custodians of Nyikina Country and knowledge. Annie Milgin is also the leading expert in Nyikina language. Sarah Laborde and Sue Jackson are non-Indigenous environmental social scientists with a research focus on the political ecology of water. They are involved in a larger study of Indigenous rights and interests 
in water in the region that includes research on the freshwater and riparian ecology of the Mardoowarra (see Douglas et al., 2019).

The research underpinning this article was approved under Griffith University's Human Research Ethics procedures. Walalakoo Aboriginal Corporation and Griffith University have a research agreement that provides protection for the Intellectual Property of Aboriginal authors and participants to this research. All participants have signed individual consent forms allowing the use of their quotes in this article. Annie Milgin, Linda Nardea and Sarah Laborde have presented this research to the Board of Directors of Walalakoo Aboriginal Corporation, who gave final approval for publication in June $2020 .^{3}$

The development of a Nyikina seasonal ecological framework was a collaborative effort to articulate and share Nyikina knowledge of the waters, plants and animals of Nyikina Country, for different audiences. Because of the centrality and significance of the river to Nyikina Country and people and a current context of water allocation planning, we focused our collaborative research on the dynamic linkages between water and life. Nyikina knowledge is highly contextual and localized, and respect of other peoples' relationships with their Countries means that Nyikina peoples would not propose prescriptive, normative frameworks of land and water management beyond Nyikina Country. Rather, Nyikina custodians can share stories from their Country, for others to interpret and learn-this is what Annie, Linda and Hilda have done with Sarah and Sue since 2017 in a spirit of inclusion, collaboration and education. As a result, Annie, Linda and Hilda's main contribution to the paper is in the results section, and Sarah and Sue's contribution is in the contextualization of these results. All authors agreed on the framing and key messages of the paper. The first four authors met for several days every 2-3 months, over 2 years. The work was always conducted on Nyikina Country, which for Nyikina authors encompasses a sense of home and the relations that constitute it, as well as being the source of all knowledge. We either worked in Jarlmadangah community or by the Mardoowarra, visited on day-trips or multi-day camping trips.

The research on the ecological framework proceeded via iterative, collaborative action research-from the joint definition of the research questions to action, and reflexive feedback and adjustments leading to a new cycle (Kemmis \& McTaggart, 2005). The methodology was grounded in the relationships that developed between Nyikina and non-Nyikina researchers, and with the Country itself (Bawaka Country et al., 2015). It included both Indigenous and non-Indigenous methodologies for the development and sharing of environmental knowledge (Johnson et al., 2016). Activities on Country included walking and fishing, sharing and listening to story, as well as dialogical interviews (including using film), language recording and interpretation, and conceptual mapping with the Nyikina seasons as the initial focus. These were alternatively guided by Nyikina and non-Nyikina researchers and were informed by being outside, together on Country (Bawaka Country et al., 2015). Recording sessions lasted generally $2-3 \mathrm{hr}$, or until any of us needed a rest.

Nyikina language was central to our collaborative work. Beyond a 'storehouse of knowledge and tradition about the environment' (McConvell \& Thieberger, 2001), language is a fundamental and dynamic part of Aboriginal peoples' means of communicating with their Country. The motivation for the co-creation of the Nyikina hydro-ecological framework was educational and scientific, although the authors each prioritized different audiences: to produce material for young people to learn about Nyikina language and Country (especially important to Annie, Linda and Hilda); to share with Indigenous and non-Indigenous sustainability researchers (especially important to Sarah and Sue). The objective of educating non-Aboriginal Australians about Nyikina Country was important to all authors, especially the need for government water planners and managers to gain a better understanding of Nyikina land and water management practices. Reflecting this mixed audience and our team's diverse cultural and linguistic background, our work includes both Nyikina (from the Jarlmadangah area) and English languages. The initial framework was produced as two posters depicting a seasonal hydro-ecological framework. This article stands alone, and provides an explanation of research results for an audience of environmental and social scientists, and resource managers.

Our epistemological process entailed the co-development of the framework based on a joint objective (to help share Nyikina knowledge of Country and ethical principles) using our different skills and languages. The seasonal framework itself started from a Nyikina-led vision (with temporal, spatial and relational components) that also included supportive elements of western hydro-ecological science, such as examples of a hydrograph and river profile. This is distinct to seasonal calendars that had been produced in the Kimberley (and elsewhere) by other transdisciplinary teams (Liedloff et al., 2013; Woodward et al., 2012). Using the hydrograph to connect seasonal Nyikina hydro-ecological knowledge with flow regimes in the Fitzroy River allowed us to 'bridge' the knowledge systems in a tangible way, and to facilitate interpretation of Nyikina hydro-ecologies by water planners and managers for whom the hydrograph is a familiar heuristic. On the other hand, the emphasis on Nyikina language terms and phrases makes it a useful learning tool for young Nyikina people (the framework is currently being adapted into a curriculum for local schools). While our results represent an unavoidably partial abstraction of the living knowledge that is embedded in Nyikina peoples' relationships with their Country, we hope the article constitutes a useful articulation of some of the key aspects of these relationships. It is also hoped that it will contribute to a better understanding of Indigenous ontologies and ethics by ecologists, environmental scientists and others (Barber \& Jackson, 2015).

\section{3 | RESULTS}

Nyikina ecological knowledge emerges from feedbacks between an empirical dimension that evolves through practical interaction with the features of Nyikina Country, and a dimension that is known and shared through stories. A foundational story for Nyikina people is that of the creation of the river, Mardoowarra (Milgin, 2018; Toussaint et al., $2001^{4}$ ). Nyikina language is a key to communicating directly 
with the Country, and sharing stories. A short Nyikina name for our framework is Birr nganka Yimardoowarra. Annie explained that Birr is a Nyikina word that may be translated as 'root' or 'source' and is associated with the ground; nganka may be translated as 'life', 'story' and 'knowledge'. The Nyikina term Yimardoowarra may be translated as 'people who belong to the River'. Linda added that this term characterizes people who are skilled at living and interacting with the river. For example, skilled at being able to dive in the caves under river banks to hunt for crocodiles and turtles, to swim across a strong current and to navigate all the relationships that make up the river Country-in other words, to feel at home and thrive in relation with the river. So, Birr nganka Yimardoowarra may be interpreted as 'the source (or root) of knowledge for people who belong to the River'.

The framework we present links temporal and spatial components of Nyikina ecology, with the notions of responsibility and reciprocity that lie at the heart of the process by which Nyikina knowledge of Country is both acquired and enacted. We describe three connected attributes of Nyikina knowledge of Country: First, its cyclical nature, associated with the flows of water and rhythms of decay and renewal; second, the notions of belonging and interdependence, especially as they apply to plants and animals in relation to water; and third, its ethical underpinnings. The latter are expressed in the relationships within the Country that are part of Nyikina law and culture, including relationships between water, people, plants, animals and spirit beings.

\subsection{Rhythms of water and life}

Nyikina knowledge of the Country is based on a cyclical understanding of time: life transforms along cycles of renewal and decay.
This understanding applies to the Country as well as socio-cultural cycles such as the kinship system, where family relations are not simply linear (from parent to child) but also circular through the system of skin groups, which establishes recurring cycles of connection through skin (see Birr Ngangka Nyikina, 2014). Nyikina seasons are based on complex, contextual and multi-sensory understandings of meteorological, hydrological and ecological occurrences. Annie emphasized, for example, the importance of the winds, and of looking at the flowers of different trees as indicators of seasonal changes. The climate may be described as semi-arid and monsoonal, and there are three main seasons: Wilakarra the rainy season, Barrkana the cold season and Lalin the hot season; and three transition seasons: Jirrbal announcing the rain, Koolawa the cold and Wilbooroo the heat. The seasons are associated with an annual cycle of flow regimes in the river: from low water flows during Lalin and Jirrbal (at their lowest, the river is a series of disconnected pools), to overbank flows that soak into the floodplains during Wilakarra, and within-bank flows during Koolawa and Barrkana that recede to low flows during Wilbooroo and the rest of the hot season.

Figure 2 illustrates the association between the rhythmic movement of water (represented by a standard year's hydrograph) and life in Nyikina Country. The river is considered a living being (Milgin, 2018; Poelina et al., 2019), and the hydro-ecological cycles associated with the different seasons reflect its vitality. The very hot time is one of incubation for river animals, such as turtles and crocodiles that will hatch with the first wet-season rains. Linda explained that Binda inman wila burru in Nyikina means that the water is making the Country wet at that time and ready for the flood. Binyban is the wet ground where animal tracks are easy to see in the mud.

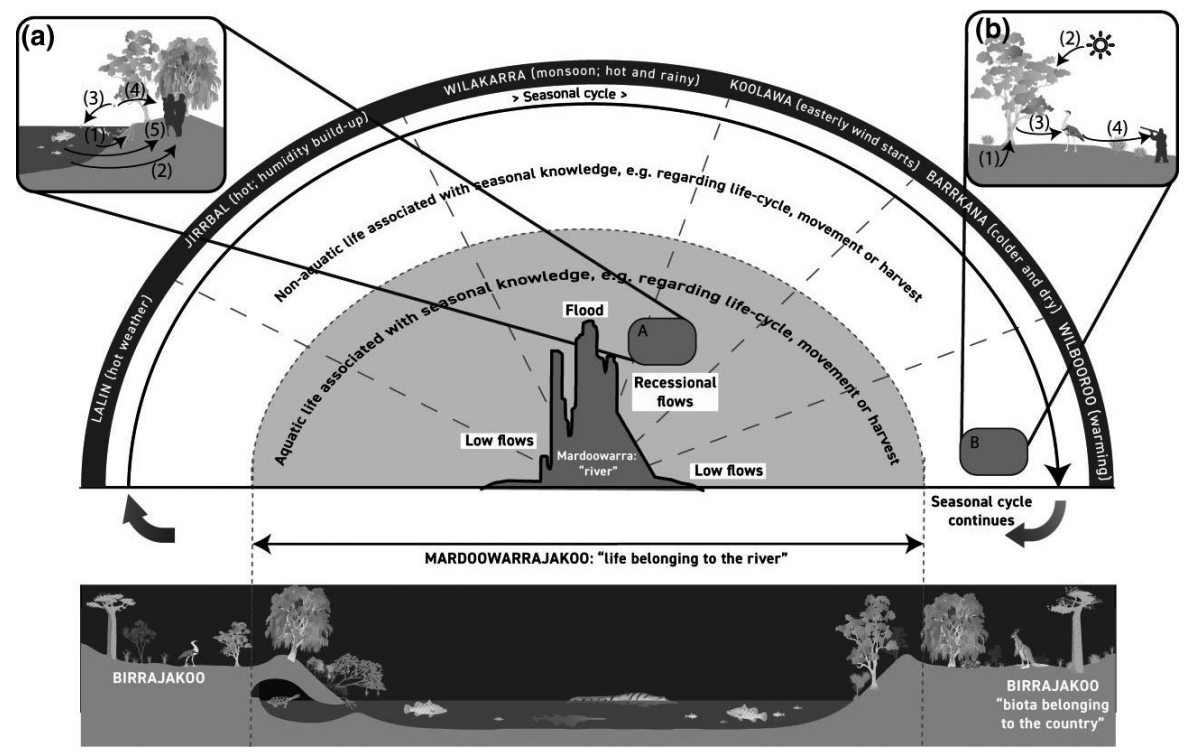

FIGURE 2 A simplified Nyikina hydro-ecological framework. The hydrograph at the centre represents an annual cycle of river flows; the arc around it represents the seasonal cycle and the profile below it illustrates some of the different habitats of Nyikina Country (expressed in Nyikina in terms of 'belonging'). The vignettes (a) and (b) are examples of hydro-ecological food chains in Nyikina Country, placed in the framework in relation to corresponding seasons (Wilakarra-Koolawa for (a) and Willbooroo for (b)), and habitats (Mardoowarrajakoo for (a) and Birrajakoo for (b)). (a) River figs ripen after the floods, feeding fish and people. (b) Medicinal gumtree sap oozes out when the hot weather starts, turkeys feed on the sap and people hunt turkeys as their meat is particularly healthy at that time 
The water then rises in the floodplains (in Nyikina: Lakarrindin wila binyban), leading to the annual pulse of water (called Warramba) that floods, cleans and regenerates the river Country. The peak flood is called Mayilooka, and it is known to enable seed distribution, the replenishment of off-channel wetlands and the inundation of floodplains that provide food for fish. Annie added that the best time to catch fish is after the third flood pulse, once the fish have fattened on the floodplains and are swimming in clean waters. The hot and wet time is also associated with the sprouting of seeds and the ripening of fruits.

Social life is adapted to the seasons in Nyikina Country, despite the limiting effect of European colonization and settlement on, for example, the ability of large groups of people to practice regional ceremonies after the floods when the Country is most plentiful (such ceremonies now tend to occur during the Christmas holidays to accommodate people's work and school schedules). Nyikina collaborators have described a precise knowledge of seasonal food chains and of the availability and location of bush foods and medicines. For example, the dry and colder times in Barrjana and Wilbooroo are not propitious for fishing, but they are good for hunting emus and turkeys that at that time feed on plentiful and healthy plant matter, including medicinal saps (Figure 1b). The very low flows during Lalin and Jirrbal are best for fishing, and a traditional fishing technique called limarra is specific to the pools that often constitute the only remaining surface water at that time of the year. At the end of Wilakarra and during Koolawa, when river flows start receding, river figs ripen and fall in the water, providing healthy feed for fish and people (Figure 2a). The water and the soil, and an understanding of their cycles, are known to be the basis of good health, as Annie explained: 'When the river is healthy, what we eat from the river and what grows on its banks is also healthy, so that's a foundation of our health'. There are also certain times, such as the first flood, when the water is considered unhealthy and children are told to keep away as the stagnant waters of the dry season are flushed downstream.

Social activities also shape and reinforce the seasonal patterns of Nyikina Country. For example, when there is moisture in the Country at the end of Wilakarra, Nyikina people light cool fires to support regrowth and prevent the hot and destructive fires of the dry season. ${ }^{5}$ At various times of the year, people may perform ceremonies to increase the availability of particular species, or even to influence weather patterns. Such co-constitution of hydro-ecological and social rhythms has been described elsewhere, from the Arctic (Krause, 2013) to the Amazon (Harris, 1998) and sub-Saharan Africa (Laborde et al., 2018).

\section{2 | Belonging to water and Country}

The notion of belonging is central to Nyikina peoples' relationship with Nyikina Country and with the river, and it is also central to the relationships between plants, animals and places. Annie, Linda and
Hilda explained that Jakoo is a dedicated suffix in Nyikina used to talk about 'belonging' when referring to beings in their preferred habitats. The model in Figure 3 locates different species on a gradient of belonging, which is associated with the skill of various species to live within or in proximity to water, and also related to a spatial gradient from the river at the centre to the dry country (Figure 3). The outer layer contains all plants and animals. A generic name for plants is baloo (Figure 3.2a, 2b, 2c) and edible animals are called warli (Figure 3.1a, 1b, 1c). Warli can be translated as 'meat' and is defined in relation to its predator or consumer. For example Jirrakiy (green frog) is not warli/meat for people (they do not eat it) but it may be warli for Jooroo (snake). Mardoowarra is the main river, therefore to say that an animal or plant is mardowarrajakoo means that its habitat is in or by the river (Figure 3.1a, 2a). For example, the biyalbiyal (sawfish) is mardoowarrajakoo warli (Figure 3.1a) and majala (freshwater mangrove) is mardoowarrajakoo baloo (Figure 3.2a).

Wila refers to water in a more general sense and wilajakoo refers to plants and animals that belong with water. That includes those that are mardoowarrajakoo but also those found near springs, or in billabongs and swamps (called Marrawan in Nyikina); for example, Joodaniny (water lily) is not mardoowarrajakoo but it is wilajakoo baloo (Figure 3.2b). Finally, birra refers to the Country in general, and so birrajakoo encompasses plants and animals that are found in the dry and rocky areas (e.g. larrkadi the boab tree is birrajakoo baloo; Figure 3.2c) but also those that can be found anywhere, like ngalyak the blue-tongue lizard (Figure 3.1c).

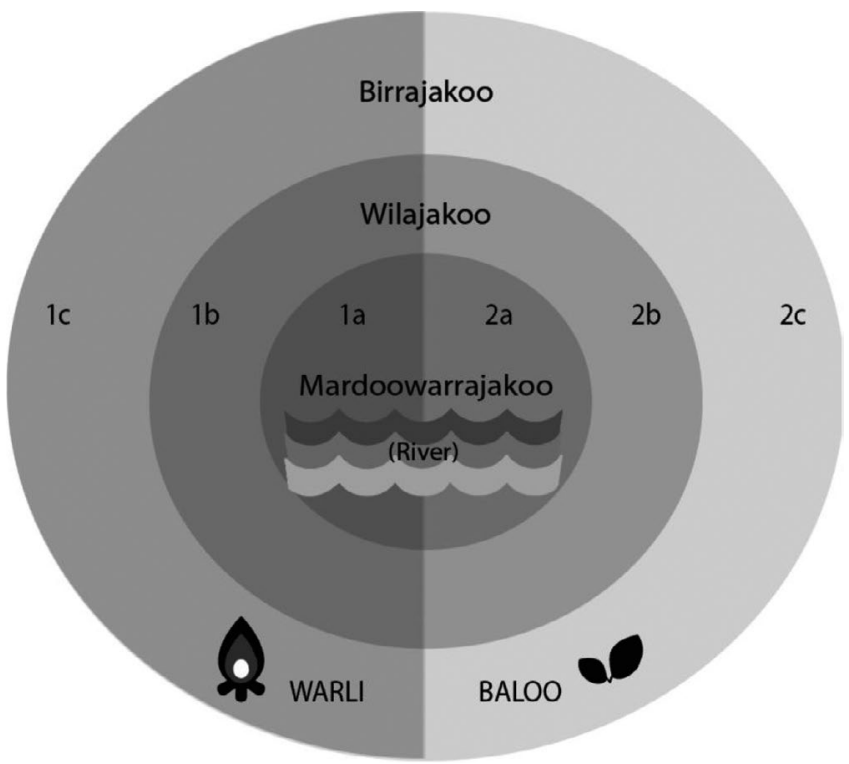

FIGURE 3 Nyikina language framework for connecting plant (Baloo in Nyikina) and animal life (Warli translates as 'meat' or 'edible animals'), and habitat, in terms of degrees of belonging to the river and water: (1a) edible animals who live in or by the river; (1b) edible animals from aquatic habitats more broadly; (1c) edible animals found anywhere in Nyikina Country; (2a) algae and riparian plants found by the river; (2b) plants growing near water bodies in general; (2c) plants found anywhere in Nyikina Country 


\section{3 | Reciprocity and ethics in Nyikina Country}

Nyikina knowledge of the Country extends beyond water, land, biota and people, to encompass the relations with ancestral and spirit beings who populate and create(d) the Country, as well as the social institutions that govern the behaviour of all beings. For Nyikina and many other Indigenous peoples, the capacity for sentience and agency is not limited to humans and animals, but ubiquitous in the Country itself that is also inhabited by spirits and ancestors (see also Jackson \& Palmer, 2017; Rose, 2005; Toussaint et al., 2001). The Nyikina hydro-ecological system is a sentient system, within which various beings are related and contribute to its integrity by maintaining reciprocal relationships supportive of life (Figure 4). Below is a list of examples drawn from our collaborative work and recordings, which illustrate the relatedness of key beings and forces in Nyikina Country, and their role in the system of relationships that forms part of Nyikina law and culture (Figure 4):

- Features of the landscapes such as rocks, meteorological forces such as winds, as well as animals, plants and people are part of the Country and each plays a specific role.

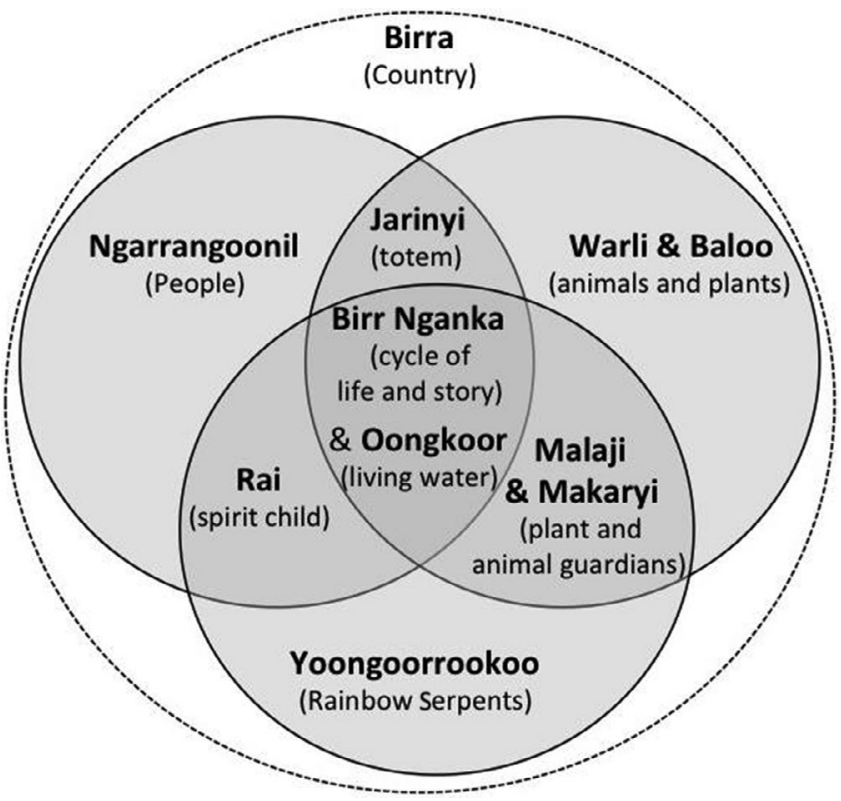

FIGURE 4 Venn diagram showing some of the relationships between beings that are known by Nyikina experts to be essential to the sustainability of Nyikina Country. Yoongoorrookoo are cosmological creation beings linked with water and light. People (Ngarrangoonil) are connected to animals and plants (Warli and Baloo) through totems (jarinyi). Rai are spirit beings that act as messengers between Yoongoorrookoo and the Country, including people. Malaji and Makaryi are plant and animal guardians that care for parts of the Country, in relation with Yoongoorrookoo. In the middle, linking all beings, is the cycle of life (Birr Nganka) and the living energy that moves water (Oongkoor). These dynamic connections are part of the Law of relationships (Warloongaryi) that maintains the vitality of the Country (Birra)
- People are related to plants and animals through a skin system and totems (jarinyi), by which they are part of the same kinship network. As they share life in the same places, they also exchange knowledge-for example, Nyikina people have long dug in the banks of the river to filter water through the alluvial sand before drinking it, as do kangaroos and wallabies. Annie and Linda explained that this technique, called jarradji, was learnt by Nyikina ancestors from kangaroos.

- Yoongoorrookoo are ancestral creation beings sometimes referred to as Rainbow Serpents, and common to many Aboriginal Australian knowledge systems (Radcliffe-Brown, 1926). Yoongoorrookoo created the Mardoowarra with Woonyoomboo, the Nyikina ancestor who also spread the Majala tree (freshwater mangrove, a powerful medicine) along the Mardoowarra and who gave Nyikina people their law. This Nyikina creation story was told and sung by Darby Nangkiriny (see Toussaint et al., 2001), and now it is held and shared by the families of Annie, Linda and Hilda. These Serpents are spirit actors with an especially strong association with water in all its forms (Strang, 2019): surface water, groundwater and atmospheric water. They are powerful beings with the responsibility, commensurate to their power, to maintain the life force and the law in the Country, for example by communicating with people (e.g. via meteorological occurrences) to let them know of any misguided action on Country (see also Toussaint et al., 2001).

- Spirit beings called Rai inhabit the space between dream and wakefulness, and act as messengers between the Serpents and the Country, including with people. They are involved in connecting people and animals as they operate the spiritual transition from the death of an animal to the birth of a child.

- Malaji (tree) and Makaryi (aquatic animal) are plant and animal guardians that act in partnership with the Serpents to maintain the vitality of the Country and its food chains. Makaryi is a generic name for animal guardians of water places; there are also specific names for different species, for example Mowali for a large crocodile or Dibimba for a large barramundi. These beings fulfil an ecological role as keystone individuals in a community; a social role through (sometimes ceremonial) interactions with people; and a cosmological role through their direct connection with ancestral Serpents. To illustrate these concepts, Annie recalled a story of a shark in Libirrinbirrin (Liveringa billabong, a place in Nyikina Country) that was well known by Nyikina people when she was young: The shark was a Makaryi, working with two Malaji trees-a Jirarl tree and a Warrimba tree on either side of the billabong-to keep the energy of the place strong and the fish plentiful. Then in 1969 (non-Aboriginal), station managers shot the shark. Since then, the trees have died and the billabong is much drier. Annie explained that it is because the Markaryi (shark) was looking after the place, and its life-sustaining power was taken away when he was shot.

- Oongkoor are places that hold the living energy that flows and moves water, and Birr nganka is the cycle of life and story. Annie explained that Birr ngangka can be conceptualized as a tree, with life energy and information cycling from the ground to the roots, 
trunk, branches, fruit, birds and back to the ground and roots. Even small, seemingly insignificant beings have their place in the Country: for example, the water crickets (lirr in Nyikina) are small insects that people do not eat or use, but they have a song and a story in Nyikina law that connects them to water, people and Yoongoorrookoo.

In Nyikina cosmology, hydro-ecological knowledge is deeply ethical. Knowledge about the Country's network of social-ecological relationships (Figures 2, 3 and 4) cannot be dissociated from knowledge about how to act appropriately within this network, and thereby fulfil one's responsibilities within the Nykina law of relationships that supports the Country's vitality. The notion of rhythm, discussed in the first section, is central to these custodial relationships. Rhythms are a foundation of life, not only the rhythms of life within humans and other animals and their social worlds (e.g. rhythms of birth and death, blood and oxygen circulation, rest and activity) but also the rhythms of sunlight and water, including the wet-season rains and floods. We showed that social and hydro-ecological rhythms are co-constituted, and knowledge of these temporal patterns leads people to taking appropriate actions at certain times to support both social and ecological life. Such seasonal actions include monitoring, burning, hunting and fishing, as well as talking to the Country and its waters and performing increase ceremonies (see also Toussaint et al., 2001). Annie recalls, for example, how her father used to gather and chop a wild cabbage plant and throw it in the water to feed the fish at the end of every rainy season. Today, some of the work of NyikinaMangala rangers, guided by their elders to care for Country, is also attuned to this seasonal knowledge.

The notion of belonging also underpins the custodial relationships and responsibilities described in Figure 4. These include visiting places (and beings, e.g. particular trees) while respecting correct protocol, and generally acting as a supportive member of the community that includes people but also biotic and abiotic parts of the living landscape, such as water, animals, plants and landforms. As an example, in 2017, Linda visited her birthplace by a creek in Nyikina Country with Sarah. Upon getting there, she introduced Sarah to the place, waters and Yoongoorrookoo, following the Nyikina protocol for visitors. She then proceeded to clean the creek bed of its plant matter to facilitate water flow. After coming back to camp, Linda expressed her good feeling (Liyan in Nyikina) for having visited this special water place, and pointed at a small rain cloud above in the otherwise cloudless sky as a sign of the Country's satisfaction with the visit. The feeling of belonging that emerges from honouring such reciprocal relationships between the Country and its people is associated with wellbeing, as aptly summarized by Annie: 'I feel good in my Country: the Country that recognizes me and I recognize that Country. It is a healing relationship so that's a good Liyan ${ }^{6}$. Conversely, as Linda explained, if an action is unethical, mistaken or off-balance, the Country will respond and people should learn and adjust their course of action (see also Toussaint et al., 2001). For example, had Linda forgotten to introduce Sarah to her birth place in the story recounted above, the Yoongoorrookoo in that place might have triggered a whipping gust of wind-a common story told by Nyikina custodians. On the next visit, should one not observe proper protocol, for example, by catching more fish than needed or failing to dispose of fish bones properly, Country (via the Rai) may respond with a failed catch. The responsiveness of the Country depends on the presence of people and other beings acting in accordance with custodial responsibilities. If a place is damaged, it can lose its ability to feel and engage in the relationship with people-in which case, people will likely avoid it.

Water plays a central role in the relationships that weave the Country together (Figure 4), which is one of the reasons why the Warloongaryi, the songline for the River Country (Birr Ngangka Nyikina, 2014), is important to Nyikina people and other language groups along the river. In Nyikina country, Warloongaryi is also sung as part of men's initiation ceremonies (as explained by Darby Nangkiriny, Annie's father, see Toussaint et al., 2001). Water is at the heart of the whole system through Oongkoor, the living water places and their source of energy that animates the Country. Water is also central to the Country's seasonal rhythms through monsoonal rains and floods (Figure 2), and the living beings that belong with different degrees to the Country's waters (Figure 3: e.g. river water for Mardoowarrajakoo, rain and groundwater for Birrajakoo). Importantly, the waters in Nyikina Country are alive, animated and inhabited by Yoongoorrookoo, and the reciprocal relationships of Nyikina people with their Country and waters are committed, dialogical and supportive of each other's health. As senior Nyikina, Bardi and Warrwa man Herbie Marshall explained (2018), 'The river has kept a lot of people alive, and the people keep the river alive. It's a kind of monitoring and management. If it's healthy it provides, if it's not healthy it doesn't provide. And if it doesn't provide, there wouldn't be people there. So it's all part of the one symbiosis'.

Note that Figure 4 is far from an exhaustive representation of the relationships that underpin Nyikina Country, law and culture. Some elements of Nyikina law are not to be shared: some are only for women to know about, some only for men, and most, including the practical aspects, are only for the custodians of places in Nyikina country to know and act upon. Nyikina relations with the Country therefore include a normative element, but it is contingent, being specific to the people who have an active relationship with and responsibility towards the places, ancestors and spirits of Nyikina Country.

\section{DISCUSSION}

Our research shows that the system of custodial relationships that underpins Nyikina people's ecological ethics (Figure 4) is intrinsically linked to the hydro-ecological relationships in Nyikina Country (Figures 2 and 3). Custodial responsibilities, not only on the part of people but also of animals, plants and other entities, constitute a major conceptual difference between the notions of dependence upon a habitat or natural resource (a focus of Western ecological science and underpinning of notions like ecosystem services) and 
belonging to it (a focus of Nyikina science). Belonging comes for each entity with its own role to play within the Country. As Annie says, 'Birr Ngangka-the cycle of life, story and law in Nyikina Country-is not just for people: it animates and informs all life'.

For people, custodial responsibilities associated with belonging to the Country include a combination of deontological ethics (e.g. rules and protocols passed on since creation ancestor Woonyoomboo, such as 'not to kill small crocodiles or turtles during hatching season') and an ethos or ethical know-how (Varela, 1999) that is deeply situated and embedded in language, cultural protocols and dynamic relationships with the Country (see also Rose, 2005). Linda for instance, knew to speak the right words in language to the water and to clean the stream to facilitate water flow, without the need to refer to a normative water management framework. Instead, she and other Nyikina custodians relate to places and beings with embodied knowledge of what actions are supportive of the vitality of Nyikina Country, and thereby their own. Associated with this knowledge is an understanding that the Country is responsive to human actions, and an attunement to these responses: a dynamic dialogue that has been ongoing across generations. This type of relationship has been described as a form of adaptive management (Berkes et al., 2000). It is an active exchange, experientially grounded in what Mario Blaser called 'emplaced collectives': situated communities of humans and non-humans that "imply a "politics" marked by strong mutual obligations that make it difficult from within them to privilege the needs of some of their components at the expense of others without risking the whole collective' (2019, p. 84; see also Blaser, 2018 and Roberts et al., 1995 for a similar conclusion in a Māori context).

Importantly, we showed that this dialogical relationship with the Country is different to a top-down concept of management and even of reciprocal services (Comberti et al., 2015), and that it includes an emotional and healing bond between people and the Country (Muir et al., 2010; Simpson, 2017). The fundamental notion of well-being for Nyikina people is Marboo-joonoo Liyan, which rests on good relationships with family, Country and ancestors. ${ }^{7}$ Nyikina custodianship of Country may also be compared to the Māori concept of kaitakitanga, which applies in Aotearoa/New Zealand: according to Kirkwood, the term 'means looking after one's own blood and bones-literally. One's whanaunga [family] and tupuna [ancestors] include the plants and animals, rocks and trees' (cited in Roberts et al., 1995). The reciprocal action of 'looking after' and 'being looked after by' relations in the Country reveals a foundation of Nyikina ecological ethics in the notion of care: maintaining good (and therefore sustainable) relationships with other entities in the Country requires attending to these relationships, and caring about and for them.

These considerations lead us to the practical implications of such relational thinking for sustainability research and practice. As we have shown, and as also discussed by others (e.g. Blaser, 2019; de la Bellacasa, 2017), a relational ethos such as that of Nyikina people is always situated. Therefore, rather than attempting to produce normative and generic protocols or methods to evaluate and incorporate the 'relational values' of Indigenous custodians into sustainability frameworks, we propose an approach that might proceed at three levels. First at a governance level, equitable interactions between Indigenous and State institutions require that ontological pluralism be embedded in the policy frameworks that shape these interactions (e.g. learning from the ways that pluralistic ideas of Buen Vivir have been embedded in the constitutions of Bolivia and Ecuador, see Gudynas, 2011). The aim of doing so is to eliminate the distinction between 'those who know' (and make decisions based on modernist understandings of an objectified nature) and 'those who believe' (Indigenous peoples who are construed as holders of 'cultural values'-see Blaser \& de la Cadena, 2018)-a distinction that is still embedded in sustainability policy frameworks.

In a context of water planning and management, a (modernist) resource-based paradigm considers water as generic and inanimate (Linton, 2010), to be best characterized by its availability and utility when extracted or consumed. Instead, a relational paradigm sees water(s) as animate and agential (Aboriginal Australians talk of 'living waters') and water management conversations lead first to the question of which water one is talking about and its relationships within a place and a community. Embedding the validity of an Indigenous Living waters framework at the policy level would allow it to operate beyond the limited category of 'cultural values' or cultural ecosystem services (Jackson, 2006). In the case of the Mardoowarra, the current water management framework includes a water allocation plan, under development by the State water agency, to quantify an extractive limit for water and an environmental flow regime for the river. Setting aside a volume of water associated with cultural values in such a plan, which is the current approach, cannot fulfil the relational obligations of Aboriginal custodians for their Country. Genuine consideration of Nyikina and other Aboriginal ontologies in the catchment would instead require Government and other settler institutions to take seriously the reality and validity of living waters, and the integrity of their relationships, as defined by their custodians and different to the 'water resources' that are talked about in Government policies.

Second, at a management level, a relational approach requires sustainability assessments to be based on situated, dynamic and multisensory evaluations of the integrity of relationships within the Country made by the people who enact these relationships-in our case, Nyikina custodians. Quantitative indicators (e.g. quantities of water, animal and plant species, or even of a certain value on which human life and well-being depend) may help assess certain processes, but the first requirement of such an approach is to support ongoing communication between custodians and Country, including by facilitating intergenerational access to Country, the transmission of language and the practice of Aboriginal law. In the case of the Mardoowarra, these relational principles are being put forth by an Indigenous confederation created in 2018, the Martuwarra Fitzroy River Council. The Council emerged out of collective care for the River Country by several Indigenous leaders of the catchment, and out of the connecting force of water itself, as the river flows across Native Title boundaries and unites different language groups (Poelina et al., 2019).

Finally, for Nyikina people, knowledge of the Country and responsibility to care for it go hand-in-hand. This is not to be taken 
for granted in a modern world where the production of knowledge and the responsibility for its ethical use are largely dissociated, or in a region where colonial power relations have left a legacy of mistrust between Indigenous peoples and researchers (Jackson \& Douglas, 2015). Following Nyikina principles, and theorists such as Maria Puig de la Bellacasa, we may ask what it would mean to think about the production of academic, scientific and policy knowledge through the lens of care (2017). Producing knowledge, including techno-scientific, always takes place within a situated network (Laborde, 2015). The suggestion for researchers to pay reflexive attention to their own relationships and accountabilities to the people, places and other elements within their knowledge-production networks-thereby 're-affecting an objectified world' (de la Bellacasa, 2017, p. 64)-is another important contribution of relational thinking to sustainability research in this region and beyond.

\section{5 | CONCLUSION}

As a transdisciplinary team, both Indigenous and non-Indigenous, we developed three related models to articulate Nyikina ecology and ethics to non-Nyikina peoples, including scientists and policymakers. First, a seasonal model showing the co-constitution of hydroecological and social dynamics (Figure 2). Second, a model describing habitats in Nyikina Country in terms of belonging (Figure 3); and third, a model of reciprocal relationships known by Nyikina experts to be essential to the sustainability of their Country (Figure 4).

Our understanding of the reciprocal and dynamic relationships that co-produce Nyikina Country and knowledge leads us to concur with Chan et al. (2018) that the recent interest shown by sustainability scholars for human-environment relationality may contribute to 'a revolution that could supplant the privileged position that economics has played as the central discipline for guiding policymaking and practice'. However, we argue here that to do so, it is necessary to consider relationality as an overarching framework for diverse human-environment interactions, rather than as a type of value that is to be determined or derived by standardizing, technocratic valuation methodologies (Jackson, 2006; Turnhout et al., 2014). We have discussed the implications that such consideration of relationality may have on sustainability research and practice, at three levels: policy, management and knowledge production.

As noted by other Indigenous scholars, a relational lens sees ecological crises as signs of broken relationships (Muir et al., 2010; Whyte, 2020). Learning from Nyikina and other relational ontologies suggests that to repair these relationships, we abandon an anthropocentric ethical stance and move towards the restoration of relational qualities within collectives of humans and non-humans (Larsen \& Johnson, 2016; Nelson \& Shilling, 2018; Roberts et al., 1995) held together by an ethos of attention and care (Jackson \& Palmer, 2015; Kimmerer, 2013; Rose, 2005; Thomas, 2015). The production of knowledge via academic research and practice is also embedded in such collectives. A relational approach invites sustainability researchers and practitioners to reflect on the 'matters of care' (de la Bellacasa, 2017) in their own knowledge-production networks, and to develop collaborative processes founded in the same relational qualities of pluralism, consent, trust, accountability and reciprocity (Whyte, 2020) that are at the core of Nyikina and other Indigenous ecological ethics.

\section{ACKNOWLEDGEMENTS}

The first three authors acknowledge the founder of Nyikina story and knowledge, creation ancestor Woonyoomboo, and the Nyikina elders and old people who have passed on this knowledge until now. The research for this article was supported by a grant from the Northern Australia Environmental Resources Hub of the Australian Government's National Environmental Science Program. The authors thank Damien Parriman and Ray de Silva for their review of the manuscript, the Nyikina-Mangala rangers, residents of Jarlmadangah Burru Aboriginal Corporation and the directors of Walalakoo Aboriginal Corporation for their support. We also thank other NESP researchers, in particular Caroline Canham for engaging conversations about plants, and regional coordinator Karen Dayman for her support. Finally, we thank two anonymous reviewers and an associate editor of this journal for their helpful feedback.

\section{CONFLICT OF INTEREST}

The authors declare no conflict of interest.

\section{AUTHORS' CONTRIBUTIONS}

S.L., A.M., L.N., S.J. and H.G. designed the methodology; S.L., A.M., L.N. and H.G. collected and analysed the data, and designed the frameworks; S.L. led the writing of the manuscript; S.J. contributed critically to the drafts. All authors gave final approval for publication.

\section{DATA AVAILABILITY STATEMENT}

We used interview and focus group data for this research. Our raw data are not publicly available for confidentiality reasons, as they contain social, cultural and language data that may not be interpreted outside of their Nyikina context. They will be archived with Griffith University and Walalakoo Aboriginal Corporation.

\section{ORCID}

Sarah Laborde (iD https://orcid.org/0000-0002-3985-0200

Sue Jackson (iD https://orcid.org/0000-0001-6498-5783

\section{ENDNOTES}

1 The concept of Country for Aboriginal Australians includes all ecological and social relationships with humans, non-humans, physical and non-physical beings associated with the customary territories of an Aboriginal social group (Rose, 2005).

2 It is interesting to note that the original meaning of ethos in Greek is 'an accustomed place' (Miller, 1974, p. 309); and a similar linguistic link between customs and place has been described in at least one Indigenous language of northern Australia. There, the closest phrase to 'culture' literally translates as 'being like our place' (Yunkaporta, 2019, p. 255).

3 Two relevant posters describing elements of Nyikina ecology and ethics have been produced by the same team of researchers, and may 
be of interest to the reader. These posters will be accessible upon publication of this article on the Walalakoo Aboriginal Corporation (https://www.walalakoo.org.au/) and National Environmental Science Program (https://www.environment.gov.au/science/nesp) websites. For more information or for access to full size high-resolution posters (A0), please contact Walalakoo Aboriginal Corporation (P.O. Box 1115, Derby WA, 6728 Australia).

4 Toussaint et al. (2001) contains a transcription of a 1997 recording of Darby Nangkiriny, who was Annie, Linda and Hilda's father.

${ }^{5}$ For more information on Indigenous Australians' use of fire for land management, see Bird et al. (2008) and Russell-Smith et al. (2009).

6 'Liyan' is translated as 'feeling, emotion, spirit' in Birr Ngangka Nyikina (2014).

${ }^{7}$ Liyan is both a Yawuru and Nyikina term, with similar meanings. Yawuru Country is adjacent to Nyikina Country to the west, see Yap and $\mathrm{Yu}(2019)$

\section{REFERENCES}

Altman, J. C., \& Kerins, S. (2012). People on country: Vital landscapes, Indigenous futures (pp. 1-22). Federation Press.

Ban, N. C., Frid, A., Reid, M., Edgar, B., Shaw, D., \& Siwallace, P. (2018). Incorporate Indigenous perspectives for impactful research and effective management. Nature Ecology \& Evolution, 2(11), 1680. https:// doi.org/10.1038/s41559-018-0706-0

Barber, M., \& Jackson, S. (2015). 'Knowledge making': Issues in modelling local and indigenous ecological knowledge. Human Ecology, 43(1), 119-130. https://doi.org/10.1007/s10745-015-9726-4

Bawaka Country, Wright, S., Suchet-Pearson, S., Lloyd, K., Burarrwanga, L., Ganambarr, R., Ganambarr-Stubbs, M., Ganambarr, B., \& Maymuru, D. (2015). Working with and learning from Country: Decentring human authority. Cultural Geographies, 22(2), 269-283. https://doi. org/10.1177/1474474014539248

Berkes, F., Colding, J., \& Folke, C. (2000). Rediscovery of traditional ecological knowledge as adaptive management. Ecological Applications, 10(5), 1251-1262. https://doi.org/10.1890/1051 0761(2000)010[1251:ROTEKA]2.0.CO;2

Bird, R. B., Bird, D. W., Codding, B. F., Parker, C. H., \& Jones, J. H. (2008). The 'fire stick farming' hypothesis: Australian Aboriginal foraging strategies, biodiversity, and anthropogenic fire mosaics. Proceedings of the National Academy of Sciences of United States of America, 105(39), 14796-14801.

Birr Ngangka Nyikina. (2014). The source of Nyikina language. Madjulla Inc.

Blaser, M. (2018). Doing and undoing Caribou/Atiku: Diffractive and divergent multiplicities and their cosmopolitical orientations. Tapuya: Latin American Science, Technology and Society, 1(1), 47-64. https:// doi.org/10.1080/25729861.2018.1501241

Blaser, M. (2019). On the properly political (disposition for the) Anthropocene. Anthropological Theory, 19(1), 74-94. https://doi. org/10.1177/1463499618779745

Blaser, M., \& de la Cadena, M. (2018). Pluriverse: Proposals for a world of many worlds. A world of many worlds (pp. 1-22). Duke University Press.

Borie, M., \& Hulme, M. (2015). Framing global biodiversity: IPBES between mother earth and ecosystem services. Environmental Science \& Policy, 54, 487-496. https://doi.org/10.1016/j.envsci. 2015.05.009

Callicott, J. B. (2001). Multicultural environmental ethics. Daedalus, 130(4), 77-97.

Chan, K. M., Gould, R. K., \& Pascual, U. (2018). Editorial overview: Relational values: What are they, and what's the fuss about? Current Opinion in Environmental Sustainability, 35, A1-A7. https://doi. org/10.1016/j.cosust.2018.11.003
Chilisa, B. (2017). Decolonising transdisciplinary research approaches: An African perspective for enhancing knowledge integration in sustainability science. Sustainability Science, 12(5), 813-827. https://doi. org/10.1007/s11625-017-0461-1

Comberti, C., Thornton, T. F., de Echeverria, V. W., \& Patterson, T. (2015). Ecosystem services or services to ecosystems? Valuing cultivation and reciprocal relationships between humans and ecosystems. Global Environmental Change, 34, 247-262. https://doi.org/10.1016/ j.gloenvcha.2015.07.007

de La Bellacasa, M. P. (2017). Matters of care: Speculative ethics in more than human worlds (Vol. 41). University of Minnesota Press.

Díaz, S., Pascual, U., Stenseke, M., Martín-López, B., Watson, R. T., Molnár, Z., Hill, R., Chan, K. M. A., Baste, I. A., Brauman, K. A., Polasky, S., Church, A., Lonsdale, M., Larigauderie, A., Leadley, P. W., van Oudenhoven, A. P. E., van der Plaat, F., Schröter, M., Lavorel, S., ... Shirayama, Y. (2018). Assessing nature's contributions to people. Science, 359(6373), 270-272. https://doi.org/10.1126/science.aap 8826

Díaz-Reviriego, I., Turnhout, E., \& Beck, S. (2019). Participation and inclusiveness in the intergovernmental science-policy platform on biodiversity and ecosystem services. Nature Sustainability, 2(6), 457-464. https://doi.org/10.1038/s41893-019-0290-6

Douglas, M. M., Jackson, S., Canham, C. A., Laborde, S., Beesley, L., Kennard, M. J., Pusey, B. J., Loomes, R., \& Setterfield, S. A. (2019). Conceptualizing hydro-socio-ecological relationships to enable more integrated and inclusive water allocation planning. One Earth, 1(3), 361-373. https://doi.org/10.1016/j.oneear.2019.10.021

Ens, E. J., Pert, P., Clarke, P. A., Budden, M., Clubb, L., Doran, B., Douras, C., Gaikwad, J., Gott, B., Leonard, S., Locke, J., Packer, J., Turpin, G., \& Wason, S. (2015). Indigenous biocultural knowledge in ecosystem science and management: Review and insight from Australia. Biological Conservation, 181, 133-149. https://doi.org/10.1016/j. biocon.2014.11.008

Gould, R. K., Pai, M., Muraca, B., \& Chan, K. M. (2019). He 'ike 'ana ia ka pono (it is a recognizing of the right thing): How one indigenous worldview informs relational values and social values. Sustainability Science, 14(5), 1213-1232. https://doi.org/10.1007/s11625-01900721-9

Gudynas, E. (2011). Buen Vivir: Today's tomorrow. Development, 54(4), 441-447. https://doi.org/10.1057/dev.2011.86

Harris, M. (1998). The rhythm of life on the Amazon floodplain: Seasonality and sociality in a Riverine village. Journal of the Royal Anthropological Institute, 4(1), 65-82. https://doi.org/10. 2307/3034428

Himes, A., \& Muraca, B. (2018). Relational values: The key to pluralistic valuation of ecosystem services. Current Opinion in Environmental Sustainability, 35, 1-7. https://doi.org/10.1016/ j.cosust.2018.09.005

Holmes, M., \& Jampijinpa, W. S. P. (2013). Law for country: The structure of Warlpiri ecological knowledge and its application to natural resource management and ecosystem stewardship. Ecology and Society, 18(3). https://doi.org/10.5751/ES-05537-180319

Ingold, T. (2006). Rethinking the animate, re-animating thought. Ethnos, 71(1), 9-20. https://doi.org/10.1080/00141840600603111

Jackson, S. (2006). Compartmentalising culture: The articulation and consideration of Indigenous values in water resource management. Australian Geographer, 37(1), 19-31. https://doi.org/10.1080/00049 180500511947

Jackson, S., \& Douglas, M. (2015). Indigenous engagement in tropical river research in Australia: The TRaCK Program. The International Indigenous Policy Journal, 6(2). https://doi.org/10.18584/iipj.2015. 6.2.3

Jackson, S., \& Palmer, L. (2015). Reconceptualising ecosystems services: Possibilities for cultivating and valuing the ethics and practices of care. Progress in Human Geography, 39(2), 122-145. 
Jackson, S., Stoeckl, N., Straton, A., \& Stanley, O. (2008). The changing value of Australian tropical rivers. Geographical Research, 46(3), 275290. https://doi.org/10.1111/j.1745-5871.2008.00523.x

Jardine, T. D. (2019). Indigenous knowledge as a remedy for shifting baseline syndrome. Frontiers in Ecology and the Environment, 17(1), 13-14. https://doi.org/10.1002/fee.1991

Johnson, J. T., Howitt, R., Cajete, G., Berkes, F., Louis, R. P., \& Kliskey, A. (2016). Weaving Indigenous and sustainability sciences to diversify our methods. Sustainability Science, 11(1), 1-11.

Kawall, J. (2017). A history of environmental ethics. In S. M. A. Gardiner \& A. Thompson (Eds.), 2016 Oxford handbook in environmental ethics. Oxford University Press.

Kealiikanakaoleohaililani, K., \& Giardina, C. P. (2016). Embracing the sacred: An indigenous framework for tomorrow's sustainability science. Sustainability Science, 11(1), 57-67. https://doi.org/10.1007/ s11625-015-0343-3

Kemmis, S., \& McTaggart, R. (2005). Participatory action research: Communicative action and the public sphere. In N. Denzin \& Y. Lincoln (Eds.). Handbook of qualitative research (3rd ed., pp. 559-604). Sage.

Kimmerer, R. (2013). Braiding sweetgrass: Indigenous wisdom, scientific knowledge and the teachings of plants. Milkweed Editions.

Krause, F. (2013). Seasons as rhythms on the Kemi river in Finnish Lapland. Ethnos, 78(1), 23-46. https://doi.org/10.1080/00141844.2011.623303

Laborde, S. (2015). Environmental research from here and there: Numerical modelling labs as heterotopias. Environment and Planning D: Society and Space, 33(2), 265-280.

Laborde, S., Mahamat, A., \& Moritz, M. (2018). The interplay of top-down planning and adaptive self-organization in an African floodplain. Human Ecology, 46(2), 171-182.

Larsen, S. C., \& Johnson, J. T. (2016). The agency of place: Toward a more-than-human geographical self. GeoHumanities, 2(1), 149-166. https://doi.org/10.1080/2373566X.2016.1157003

Latour, B. (1999). Pandora's hope: Essays on the reality of science studies. Harvard University Press.

Liedloff, A., Woodward, E., Harrington, G., \& Jackson, S. (2013). Integrating indigenous ecological and scientific hydro-geological knowledge using a Bayesian Network in the context of water resource development. Journal of Hydrology, 499, 177-187. https://doi. org/10.1016/j.jhydrol.2013.06.051

Linton, J. (2010). What is water? The history of a modern abstraction. UBC Press.

McConvell, P., \& Thieberger, N. (2001). State of indigenous languages in Australia - 2001. Department of the Environment and Heritage.

Meadows, D. H., Meadows, D. L., Randers, J., \& Behrens III, W. W. (1972). The limits to growth: A report for the club of Rome's project on the predicament of mankind. Universe Books.

Milgin, A. N. (2018). Woonyoomboo the hight heron - A story from Nyikina Country. Sharing Stories Foundation.

Miller, A. B. (1974). Aristotle on habit (nOos) and character (eOos): Implications for the Rhetoric. Speech Monographs, 41, 309-316.

Minteer, B. A. (2012). Geoengineering and ecological ethics in the Anthropocene. BioScience, 62, 857-858.

Mistry, J., \& Berardi, A. (2016). Bridging indigenous and scientific knowledge. Science, 352(6291), 1274-1275. https://doi.org/10.1126/scien ce.aaf1160

Muir, C., Rose, D., \& Sullivan, P. (2010). From the other side of the knowledge frontier: Indigenous knowledge, social-ecological relationships and new perspectives. The Rangeland Journal, 32(3), 259-265. https://doi.org/10.1071/RJ10014

Næss, A. (1973). The shallow and the deep, long-range ecology movement: A summary. Inquiry, 16(1-4), 95-100. https://doi.org/10.1080/00201 747308601682

Nelson, M. K., \& Shilling, D. (2018). Traditional ecological knowledge: Learning from indigenous practices for environmental sustainability (new directions in sustainability and society). Cambridge University Press. https://doi.org/10.1017/9781108552998

Pierotti, R., \& Wildcat, D. (2000). Traditional ecological knowledge: The third alternative (commentary). Ecological Applications, 10(5), 1333-1340. https://doi.org/10.1890/1051-0761(2000)010[1333:TEKTTA]2.0.CO;2

Poelina, A., Taylor, K. S., \& Perdrisat, I. (2019). Martuwarra Fitzroy River Council: An Indigenous cultural approach to collaborative water governance. Australasian Journal of Environmental Management, 26(3), 236-254. https://doi.org/10.1080/14486 563.2019.1651226

Radcliffe-Brown, A. R. (1926). The Rainbow-Serpent Myth of Australia. The Journal of the Royal Anthropological Institute of Great Britain and Ireland, 56, 19-25. [online]. Retrieved from www.scribd.com/ doc/38527584/Rainbow-Serpent

Reyes-García, V., \& Benyei, P. (2019). Indigenous knowledge for conservation. Nature Sustainability, 2, 657-658. https://doi.org/10.1038/ s41893-019-0341-z

Roberts, M., Norman, W., Minhinnick, N., Wihongi, D., \& Kirkwood, C. (1995). Kaitiakitanga: Māori perspectives on conservation. Pacific Conservation Biology, 2(1), 7-20.

Rose, D. (2005). An indigenous philosophical ecology: Situating the human. The Australian Journal of Anthropology, 16(3), 294-305. https://doi.org/10.1111/j.1835-9310.2005.tb00312.x

Royal, T. A. C. (2007). 'Te Ao Mārama - The natural world', Te Ara - The Encyclopedia of New Zealand. Retrieved from http://www.TeAra.govt. nz/en/te-ao-marama-the-natural-world/print

Russell-Smith, J., Whitehead, P., \& Cooke, P. (2009). Culture, ecology and economy of fire management in north Australian savannas: Rekindling the Wurrk tradition. CSIRO Publishing.

Salmón, E. (2000). Kincentric ecology: Indigenous perceptions of the human-nature relationship. Ecological Applications, 10(5), 13271332. https://doi.org/10.1890/1051-0761(2000)010[1327:KEIPO $\mathrm{T}] 2.0 . \mathrm{CO} ; 2$

Sheremata, M. (2018). Listening to relational values in the era of rapid environmental change in the Inuit Nunangat. Current Opinion in Environmental Sustainability, 35, 75-81. https://doi.org/10.1016/ j.cosust.2018.10.017

Simpson, L. B. (2017). As we have always done: Indigenous freedom through radical resistance. University of Minnesota Press.

Stålhammar, S., \& Thorén, H. (2019). Three perspectives on relational values of nature. Sustainability Science, 14(5), 1201-1212. https://doi. org/10.1007/s11625-019-00718-4

Strang, V. (2019). The meaning of water to health. In R. Foley, R. Kearns, T. Kistemann, \& B. Wheeler (Eds.), Blue space, health and wellbeing: Hydrophilia Unbounded (p. 2). Routledge.

Tengö, M., Hill, R., Malmer, P., Raymond, C. M., Spierenburg, M., Danielsen, F., Elmqvist, T., \& Folke, C. (2017). Weaving knowledge systems in IPBES, CBD and beyond-lessons learned for sustainability. Current Opinion in Environmental Sustainability, 26, 17-25. https:// doi.org/10.1016/j.cosust.2016.12.005

Thomas, A. C. (2015). Indigenous more-than-humanisms: Relational ethics with the Hurunui River in Aotearoa New Zealand. Social \& Cultural Geography, 16(8), 974-990. https://doi.org/10.1080/14649 365.2015.1042399

Toussaint, S., Sullivan, P., Yu, S., \& Mularty, M. (2001). Fitzroy Valley Indigenous cultural values study. Report for the Water and Rivers Commission. Centre for Anthropological Research, University of Western Australia.

Turnhout, E., Neves, K., \& De Lijster, E. (2014). 'Measurementality' in biodiversity governance: Knowledge, transparency, and the Intergovernmental Science-Policy Platform on Biodiversity and Ecosystem Services (IPBES). Environment and Planning A: Economy and Space, 46(3), 581-597. https://doi.org/10.1068/a4629

Varela, F. J. (1999). Ethical know-how. Action, wisdom, and cognition. Stanford University Press. 
Veth, P., Ditchfield, K., Bateman, M., Ouzman, S., Benoit, M., Motta, A. P., Lewis, D., Harper, S., \& Balanggarra Aboriginal Corporation. (2019). Minjiwarra: Archaeological evidence of human occupation of Australia's northern Kimberley by 50,000 BP. Australian Archaeology, 85(2), 115-125.

Walalakoo Aboriginal Corporation. (2017). Walalakoo healthy country plan 2017-2027. The Nature Conservancy Australia and Walalakoo Aboriginal Corporation. Retrieved form www.walalakoo.org.au

Walsh, F. J., Dobson, P. V., \& Douglas, J. C. (2013). Anpernirrentye: A framework for enhanced application of indigenous ecological knowledge in natural resource management. Ecology and Society, 18(3), 18. https://doi.org/10.5751/ES-05501-180318

Watson, I. (2002). Buried alive. Law and Critique, 13(3), 253-269.

Whyte, K. (2020). Too late for indigenous climate justice: Ecological and relational tipping points. Wiley Interdisciplinary Reviews: Climate Change, 11(1), e603. https://doi.org/10.1002/wcc.603

Woodward, E., Jackson, S., Finn, M., \& Marfurra McTaggart, P. (2012). Utilising Indigenous seasonal knowledge to understand aquatic resource use and inform water resource management in northern Australia. Ecological Management and Restoration, 13(1), 58-64. https://doi.org/10.1111/j.1442-8903.2011.00622.x
Yap, M., \& Yu, E. (2019). Mabu liyan: The Yawuru way. In C. Fleming \& M. Manning (Eds.), Routledge handbook of indigenous wellbeing (pp. 261-280). Routledge.

Yunkaporta, T. (2019). Sand talk: How indigenous thinking can save the world. Text Publishing.

\section{SUPPORTING INFORMATION}

Additional supporting information may be found online in the Supporting Information section.

How to cite this article: Milgin A, Nardea L, Grey H, Laborde $\mathrm{S}$, Jackson S. Sustainability crises are crises of relationship: Learning from Nyikina ecology and ethics. People Nat. 2020;2:1210-1222. https://doi.org/10.1002/pan3.10149 